\title{
Suplementação com óleo de soja na dieta de potros ${ }^{1}$
}

\section{Waleska Tobo Pastori ${ }^{2}$, Rodrigo Martins Ribeiro ${ }^{2}$, Marco Henrique Ramos Fagundes ${ }^{2}$, Ligia Dias Prezotto ${ }^{3}$, Alexandre Augusto de Oliveira Gobesso ${ }^{4}$}

\author{
1 Projeto financiado pela FAPESP, Proc no 04/06404-7. \\ 2 Mestrando em Nutrição e Produção Animal da Faculdade de Medicina Veterinária e Zootecnia, Universidade de São Paulo (FMVZ-USP). \\ ${ }^{3}$ Curso de graduação em Zootecnia - FMVZ - USP. Bolsista de Iniciação Científica CNPq. \\ ${ }^{4}$ Departamento de Nutrição e Produção Animal - FMVZ - USP.
}

RESUMO - Em um delineamento quadrado latino $4 \times 4$ balanceado, foram utilizados quatro potros, filhos do mesmo garanhão, com idade entre 10 e 12 meses e $270 \pm 9$,80 kg. Foram analisados os efeitos dos níveis de 5, 10, 15 e $20 \%$ de óleo de soja no concentrado sobre a aceitabilidade e a digestibilidade dos nutrientes e sobre a concentração plasmática de colesterol total e suas frações nas lipoproteínas de densidade muito baixa (VLDL-C), densidade baixa (LDL-C) e densidade alta (HDL-C) e nos triglicérides totais. O aumento do nível de óleo na dieta afetou as digestibilidades da matéria orgânica, fibra em detergente neutro e fibra em detergente ácido, que apresentaram resposta quadrática, com diminuição após os valores de 10,7; 9,5 e 10,5\%, respectivamente, de extrato etéreo na dieta. Os níveis de óleo de soja tiveram efeito linear sobre as concentrações plasmáticas de colesterol e LDL-C, que apresentaram diminuição de 0,65 mg/dL e 0,58 mg/dL, respectivamente, a cada $1 \%$ de aumento no extrato etéreo do concentrado. Níveis de óleo de soja superiores a 9,5\% no concentrado afetam a digestibilidade da dieta, principalmente na parede celular, e diminuem as concentrações plasmáticas de colesterol e LDL-C.

Palavras-chave: colesterol, digestibilidade, equinos, gordura, lipoproteínas

\section{Soybean oil supplementation in the diet of foals}

\begin{abstract}
Four foals, sired by the same stallion, aged between 10 and 12 months and $270 \pm 9.80 \mathrm{~kg}$ average weight, were alloted in a $4 \times 4$ balanced Latin Square design. The effects were analyzed of the inclusion of the levels of 5, 10, 15 and $20 \%$ of soybean oil in the concentrate on the acceptability, nutrient digestibilities and on total cholesterol plasma concentrations and its fractions: very low density lipoprotein (VLDL-C), low-density lipoprotein (LDL-C), high-density lipoprotein (HDL-C) and total triglycerides (TRG). The increase in the level of soybean oil in the diet affected the digestibilities of organic matter, neutral detergent fiber and acid detergent fiber that presented a quadratic response which decreased after a expected values of 10.7, 9.5 and 10.5\% ether extract in the concentrate, respectively. There was a linear response of the soybean oil levels on the cholesterol plasma concentration and LDL-C that showed a decrease of $0.65 \mathrm{mg} / \mathrm{dL}$ cholesterol and $0.58 \mathrm{mg} / \mathrm{dL}$ LDL-C for each $1 \%$ increase in ether extract in the concentrate. The inclusion of soybean oil affected the digestibility of the diet, especially the cell wall and the plasma cholesterol and LDL-C concentrations.
\end{abstract}

Key Words: cholesterol, digestibility, equine, fats, lipoproteins

\section{Introdução}

O aumento da densidade energética da maioria dos concentrados é tradicionalmente obtido com o uso de grãos contendo carboidratos solúveis. Em cavalos, o excesso de grãos na dieta pode ocasionar redução na ingestão de forragens e diminuição do consumo de água e eletrólitos, aumentado a incidência de doenças relacionadas a distúrbios digestivos (Geelen, 2001). Em comparação aos carboidratos, a gordura pode ser fonte de energia mais segura em dietas de alta densidade energética, pois diminui ou contorna as adversidades decorrentes da alta concentração de carboidratos (Hallebeek, 2002).

Os efeitos da suplementação de gordura na dieta de equinos têm sido estudados intensivamente para o desempenho no esporte, porém poucos pesquisadores têm conduzido estudos sobre o efeito na digestibilidade dos nutrientes (Bush et al., 2001). Os efeitos da gordura em relação à digestibilidade de outros nutrientes são complexos e não estão completamente esclarecidos (Zeyner, 2002). 
Diversos trabalhos com adição de gordura na dieta apresentaram resultados contraditórios, principalmente quanto à digestibilidade da fração da parede celular. Alguns pesquisadores informaram que a adição de gordura na ração não afetou a digestibilidade da fibra (Bush et al., 2001; Resende Jr. et al., 2004), enquanto outros observaram aumento da digestibilidade deste nutriente (Scott et al., 1989; Hughes et al.,1995).

Sabe-se que a quantidade e o tipo de gordura são fundamentais no metabolismo lipídico (Geelen, 2001; Jansen et al., 2000). Entretanto, nos equinos, a relação entre gordura dietética e metabolismo lipídico não foi estudada intensivamente em comparação aos estudos realizados no homem e outras espécies (Hallebeek, 2002).

Este trabalho foi realizado com o objetivo de avaliar os efeitos dos níveis de 5, 10, 15 e 20\% de inclusão de óleo de soja no concentrado das dietas de potros sobre a aceitabilidade da dieta, a digestibilidade dos nutrientes e as concentrações plasmáticas nos níveis de triglicérides, colesterol total e suas frações nas lipoproteínas de densidade muito baixa (HDL-C), densidade baixa (LDL-C) e densidade alta (VLDL-C).

\section{Material e Métodos}

O experimento foi realizado nas instalações da Faculdade de Medicina Veterinária e Zootecnia da Universidade de São Paulo, no Campus de Pirassununga, São Paulo. O delineamento utilizado foi o quadrado latino $4 \times 4$ balanceado e a duração de cada período foi de 11 dias, com 8 dias de adaptação à dieta e 3 dias para coleta total de fezes.

Foram utilizados quatro potros, filhos do mesmo garanhão, alojados em baias individuais com $12 \mathrm{~m}^{2}$. Os animais, que apresentavam ao início do experimento entre 10 e 12 meses de idade e $270 \pm 9,80 \mathrm{~kg}$, foram previamente imunizados contra tétano e vermifugados e pulverizados contra ectoparasitos. Os animais não participaram de atividades físicas; apenas praticaram caminhadas no final de cada período após a coleta total de fezes para diminuir o efeito do confinamento.

O óleo de soja refinado foi adicionado ao concentrado da dieta nos níveis de 5, 10, 15 ou 20\%, além da quantidade de extrato etéreo presente no concentrado e no feno (Tabela 1 ). Dessa forma, a porcentagem de extrato etéreo, com base na matéria seca, para a dieta total foi de 5,9; 8,33; 10,64 e $12,84 \%$, correspondente a 277,$13 ; 402 ; 526,88$ e 651,75 g de extrato etéreo, respectivamente (Tabela 2).

As dietas foram compostas de $50 \%$ de feno da gramínea Cynodon dactylon (L.) pers, Var. Coast cross, e 50\% concentrado experimental e diferiram somente pela porcentagem de óleo de soja refinado.
Tabela 1- Composição nutricional das dietas (\% MS)

\begin{tabular}{lccc}
\hline $\begin{array}{l}\text { Nutriente (\%) } \\
\text { experimental }\end{array}$ & Concentrado & $\begin{array}{c}\text { Feno de } \\
\text { Coastcross }\end{array}$ & Óleo de soja \\
\hline Matéria seca & 90,37 & 92,64 & 100 \\
Extrato etéreo & 4,66 & 1,43 & 99,9 \\
Proteína bruta & 14,02 & 13,85 & - \\
Cálcio & 1,9 & 0,29 & - \\
Fósforo & 0,61 & 0,2 & - \\
Fibra em detergente neutro & 19,9 & 80,38 & - \\
Fibra em detergente ácido & 12,37 & 38,98 & - \\
\hline
\end{tabular}

Composição do concentrado experimental: soja extrusada, 25\%; rolão de milho, $65 \%$; fubá de milho, $10 \%$; premix, $4 \%$; sal comum, $1 \%$.

A dieta foi fornecida duas vezes ao dia, em intervalos constantes, às 7 e $19 \mathrm{~h}$, dividindo-se a ração total e o suplemento de óleo em partes iguais entre os dois horários. O concentrado foi fornecido ao mesmo tempo que o volumoso, porém em cochos separados, e o óleo foi adicionado à ração no momento do fornecimento.

A aceitabilidade foi avaliada pela observação no tempo de ingestão do concentrado após o fornecimento e pela quantificação das sobras.

No período de colheita total de fezes, foi retirada a cama de serragem das baias. As fezes totais foram recolhidas em sacolas de coleta a cada 24 horas e acondicionadas em sacos plásticos, pesadas, identificadas por animal e congeladas. Ao final das 72 horas de colheita, as amostras foram homogeneizadas retirando-se $5 \%$ para análise bromatológica.

As amostras para dosagem plasmática de triglicérides, colesterol e suas frações nas lipoproteínas HDL-C, LDL-C e VLDL-C foram colhidas, após jejum prévio de 12 horas, no período de colheita total de fezes, por punção da veia jugular e encaminhadas ao laboratório.

As análises bromatológicas das amostras dos alimentos e das fezes foram realizadas no Laboratório de Bromatologia do Departamento de Nutrição e Produção Animal da Universidade de São Paulo (VNP/USP), segundo procedimentos descritos por Silva \& Queiroz (1998). Para avaliação das frações de lipoproteínas, foi aplicado o método de Lowry (1977). As análises estatísticas foram realizadas utilizando-se o programa Statistical Analysis System (SAS, 1995). O arranjo utilizado foi estruturado em níveis e analisado por regressão simples polinomial. Os contrastes incluíram efeitos linear, quadrático e o desvio da quadrática, sobre a digestibilidade dos nutrientes e concentração plasmática de colesterol total, HDL-C, LDL-C, VLDL-C e triglicérides, de acordo com aumento da quantidade de extrato etéreo na dieta total. 


\section{Resultados e Discussão}

Segundo Lewis (2000), diversas fontes de gordura podem ser oferecidas para equinos, entre elas, gordura animal e diversos óleos de origem vegetal, como soja, canola, linhaça e palma, porém, essas fontes diferem quanto à palatabilidade. Os níveis de óleo de soja avaliados não tiveram efeito sobre a aceitabilidade da dieta, pois todo o concentrado fornecido foi consumido em aproximadamente uma hora e não houve sobras. Não foi observada modificação na consistência das fezes nem houve distúrbios gastrintestinais durante o período experimental.

De acordo com Hallebeek (2002), concentrados suplementados com óleo de soja, óleo de palma ou MCT (triglicerídeos de cadeia média) são bem aceitos por cavalos. Esses autores observaram também que o tempo de alimentação dos animais que receberam a dieta suplementada (12\%) foi maior em comparação ao daqueles que receberam a dieta controle (3\% de gordura). Neste trabalho, no entanto, não foi observada nenhuma diferença no tempo de ingestão entre os níveis de óleo de soja.

Ressalta-se que, além do óleo de soja acrescido à dieta, o concentrado e o feno também contêm extrato etéreo, portanto a quantidade de extrato etéreo total da dieta nos níveis de 5, 10, 15 e 20\% foi de 277,13; 402; 526,88 e 651,75 g, respectivamente (Tabela 2). Verificou-se efeito quadrático $(\mathrm{P}=0,0808)$ da suplementação de óleo de soja na dieta sobre a digestibilidade de matéria seca e matéria orgânica $(\mathrm{P}=0,0131)$, que aumentaram até o valor esperado $10,36 \%$ e 10,74\% de óleo de soja e diminuíram em níveis mais altos (Figura 1, Tabela 3).

Os resultados encontrados confirmam os obtidos por Jansen et al. (2000), que relataram diminuição do coeficiente de digestibilidade da MS em dietas suplementadas com 15\% de óleo de soja na dieta total. Os dados contrariam, no entanto, os relatos de Bush et al. (2001), que, estudando digestibilidade in vitro, relataram que não há efeito da inclusão de óleo de milho sobre a digestibilidade da MS e MO e de McCann et al. (1987), que relataram aumento na digestibilidade aparente da matéria seca em dietas com $15 \%$ de óleo de milho.

A digestibilidade aparente da proteína bruta (DAPB) apresentou resposta linear decrescente (Tabela 3), com diminuição de $0,28 \%$ a cada $1 \%$ de óleo de soja acrescido ao concentrado. Jansen et al. (2002) descreveram resultados semelhantes em estudo no qual observaram menor digestibilidade da proteína nas dietas suplementadas com gordura em comparação a uma dieta controle (sem adição de gordura).

Meyer et al. (1997), em pesquisa com cavalos fistulados na porção distal do íleo, também observaram diminuição da digestibilidade da PB no intestino delgado decorrente da inclusão de gordura na dieta, porém, os mecanismos ainda não estão esclarecidos. Segundo Webb et al. (1987) e Bush et al. (2001), a digestibilidade da proteína bruta em dietas suplementadas com gordura não difere da obtida com dietas não suplementadas.

Não foi observado efeito dos níveis de óleo de soja sobre a digestibilidade aparente do extrato etéreo $(\mathrm{P}=0,1391)$. Os dados observados estão de acordo com os descritos por Kronfeld et al. (2004), que relataram médias de 88 a 94\% para dietas acrescidas de gorduras e óleos. Os resultados deste experimento foram semelhantes aos relatados por Meyer et al. (1989), que compararam dieta sem adição de gordura $(6,64 \%$ de EE) a dietas acrescidas de gordura animal (11,68 e 17\% de EE) e não observaram diferença na digestibilidade aparente do extrato etéreo. Da mesma forma, Webb et al. (1987) compararam dietas sem adição de gordura (5\% de EE) a uma dieta suplementada com óleo vegetal (8,39\% de EE) e não verificaram diferença entre os níveis de gordura.

Tabela 2 - Consumo diário dos nutrientes das dietas experimentais (\% MS)

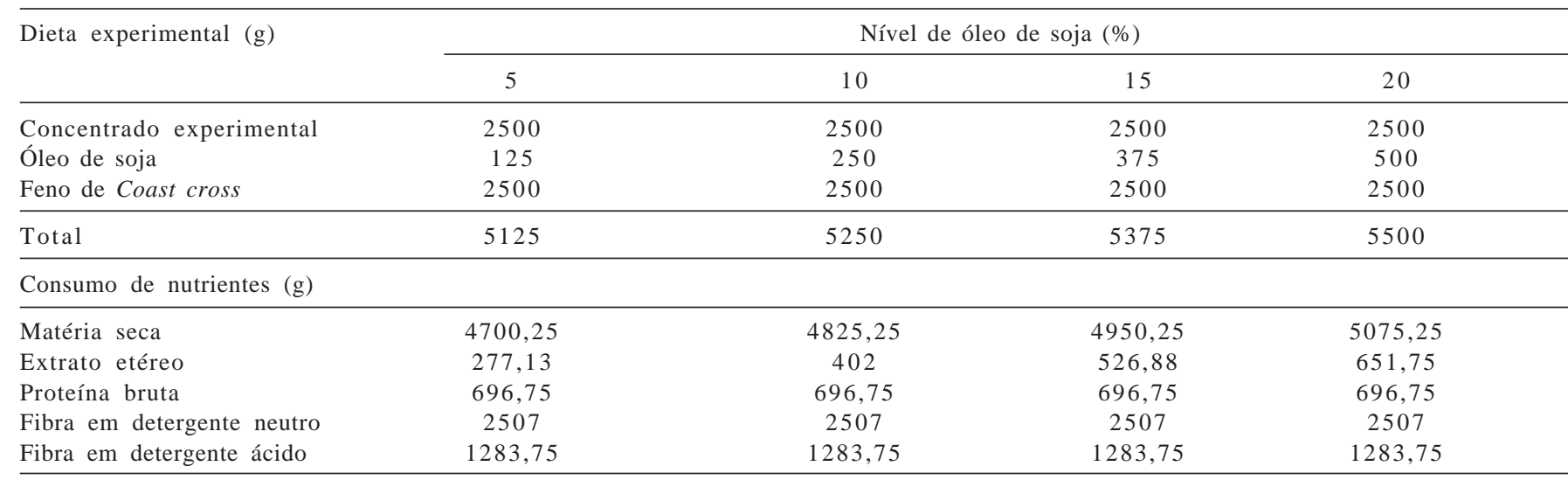


Tabela 3 - Digestibilidade dos nutrientes em potros mantidos com dietas suplementadas com óleo de soja

\begin{tabular}{|c|c|c|c|c|c|c|c|c|c|}
\hline & \multicolumn{4}{|c|}{ Nível de óleo de soja (\%) } & \multirow{2}{*}{$\begin{array}{l}\text { Desvio- } \\
\text { padrão }\end{array}$} & \multirow[t]{2}{*}{$\mathrm{P}$} & \multirow[t]{2}{*}{ Regressão } & \multirow[t]{2}{*}{$r^{2}$} & \multirow{2}{*}{$\begin{array}{l}\text { Ponto } \\
\text { de máxim }\end{array}$} \\
\hline & 5 & 10 & 15 & 20 & & & & & \\
\hline Matéria seca & 61,61 & 65,45 & 60,9 & 59,18 & 3,54 & 0,0808 & $57,80+1,15 X-0,05 X^{2}$ & 0,3133 & 10,36 \\
\hline Matéria orgânica & 63,65 & 67,31 & 63,82 & 61,02 & 3,48 & 0,0131 & $58,72+1,39 X-0,06 X^{2}$ & 0,3729 & 10,74 \\
\hline Proteína bruta & 67,47 & 68,17 & 65,47 & 63,73 & 3,35 & 0,0601 & $69,69-0,28 x$ & 0,2245 & - \\
\hline Extrato etéreo & 86,67 & 87,97 & 89,5 & 89,56 & 2,38 & 0,1391 & - & - & - \\
\hline Fibra em detergente neutro & 48,92 & 54,49 & 46,13 & 42,54 & 6,78 & 0,0396 & $43,43+1,74 X-0,09 X^{2}$ & 0,3418 & 9,5 \\
\hline Fibra em detergente ácido & 40,29 & 49,7 & 38,99 & 35,5 & 8,37 & 0,0353 & $31,26+2,72 X-0,13 X^{2}$ & 0,2776 & 10,56 \\
\hline
\end{tabular}

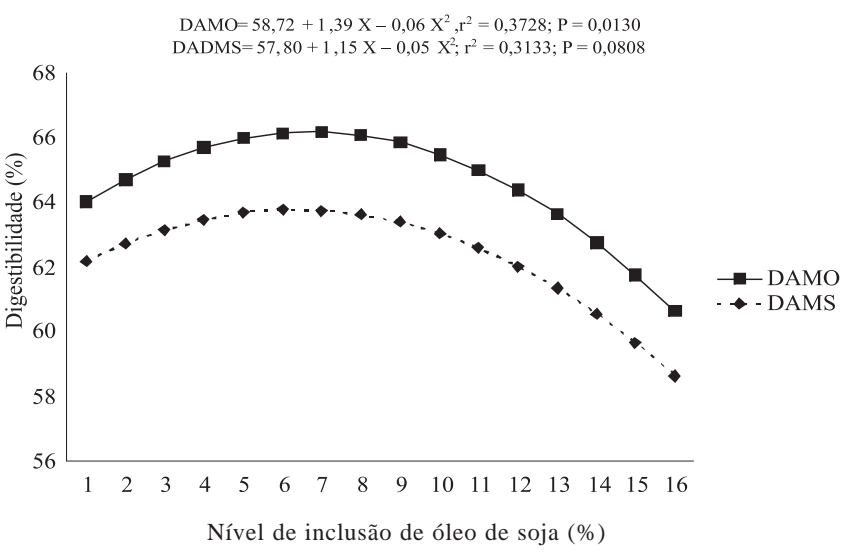

Figura 1 - Digestibilidade aparente da matéria seca e matéria orgânica em potros mantidos com dietas suplementadas com óleo de soja.

Entretanto, os dados obtidos diferem daqueles encontrados por Kane et al. (1979), Scott et al. (1989) e Bush et al. (2001), que notaram aumento na digestibilidade do extrato etéreo com a adição de óleos à dieta. As digestibilidades aparentes de FDN e FDA apresentaram resposta quadrática (Tabela 3) e, de acordo com as regressões obtidas, pode-se concluir que o maior valor de digestibilidade da FDN foi de 51,71\% e o da FDA, de 45,64\%, para os níveis esperados de 9,5 e 10,56\%, respectivamente, com diminuição em níveis superiores (Figura 2).

Os óleos suplementados à dieta são bem digeridos por equinos e são primordialmente degradados e absorvidos no intestino delgado, porém, uma porcentagem pode escapar desse processo e alcançar o ceco e cólon.

Julen et al. (1995) e Webb et al. (1987), comparando dietas para equinos com inclusão de $10 \%$ de sebo bovino a dietas sem inclusão de gordura, observaram aumento do coeficiente de digestibilidade da FDN. Neste experimento, também ocorreu aumento do coeficiente de digestibilidade da FDN até o nível de 9,5\%. Segundo Galbraith et al. (1971), os ácidos graxos saturados são menos potentes em inibir o crescimento microbiano que os poliinsaturados.

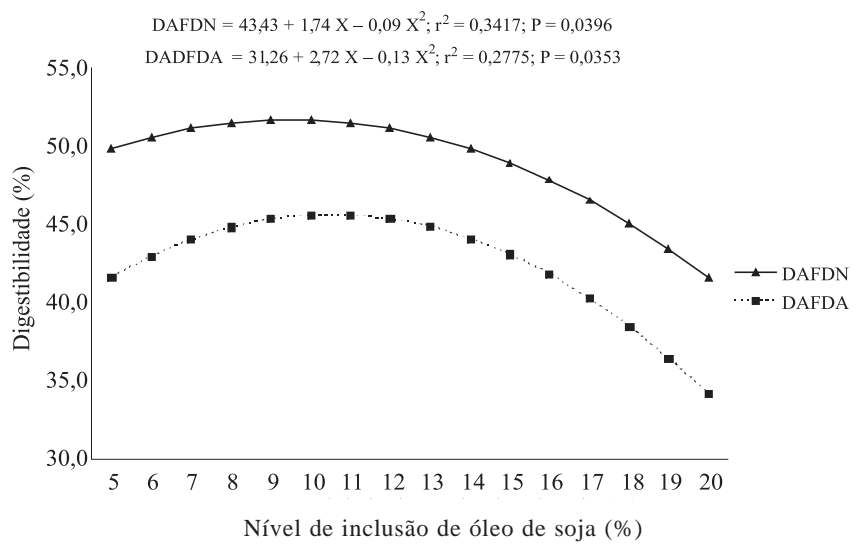

Figura 2 - Digestibilidade aparente da fibra em detergente neutro (FDN) e da fibra em detergente ácido (FDA) em potros mantidos com dietas suplementadas com óleo de soja.

Jansen et al. (2000), comparando duas dietas isoenergéticas e isoproteicas - uma controle, sem adição de óleo, e outra suplementada com 15\% de óleo de soja -, também observaram menor $(\mathrm{P}<0,05)$ digestibilidade no grupo sob suplementação (FDN 54,6\%, FDA 42,2\%) em comparação ao controle (FDN 60,8\%, FDA 50,5\%). Os autores justificaram esse fato pela presença de gordura que alcançou o ceco, porém não descartaram a possibilidade de a alta ingestão de gordura diminuir a digestão pré-cecal de amido, o que levaria a aumento da fermentação no ceco, alterando o pH e prejudicando a utilização da fibra.

Em outro experimento, Jansen et al. (2002), substituindo o amido por glicose no concentrado, testaram a inclusão de óleo de soja e verificaram diminuição da digestibilidade de FDN e FDA para o grupo com adição de óleo, confirmando os resultados de seu estudo prévio, porém, não houve influência do amido no $\mathrm{pH}$ cecal, mas verificou-se diminuição da digestibilidade da FDN e FDA. Esses autores concluíram que houve efeito tóxico da gordura nos microrganismos celulolíticos.

Pode ser que, em grandes proporções na dieta, o óleo atinja o ceco e reduza a atividade celulolítica da microflora 
cecal por mecanismos semelhantes aos que ocorrem no rúmen de bovinos, nos quais há diminuição da adesão das bactérias celulolíticas à parede celular da fibra e também toxicidade à microflora (Palmquist \& Jenkins, 1980), prejudicando a utilização da fibra e diminuindo a digestibilidade aparente de FDN e FDA.

Foi observada regressão linear $(P=0,0012)$ para a concentração plasmática de colesterol nos diversos níveis de óleo de soja (Tabela 4). A regressão comprova que, ao aumentar $1 \%$ na inclusão de óleo de soja no concentrado, diminui em $0,65 \mathrm{mg} / \mathrm{dL}$ a concentração de colesterol plasmático. Apesar do efeito hipocolesterolêmico observado, os valores se encontram dentro dos limites fisiológicos considerados normais para a espécie, segundo Bruss (1980).

São limitados os estudos sobre a influência da gordura dietética sobre o metabolismo lipídico em cavalos. Sabe-se que, no homem, a troca da dieta rica em ácidos graxos saturados por ácidos graxos mono ou poliinsaturados diminui o colesterol (Hallebeek, 2002). Segundo Grundy (1996), o óleo de soja é rico em ácidos graxos poliinsaturados e contém 53,2\% de ômega-6 em sua composição. Neste experimento, os animais receberam dieta rica em ácidos graxos poliinsaturados, o que poderia justificar a redução dos níveis plasmáticos de colesterol.

O mecanismo de ação hipocolesterolêmico dos ácidos graxos poliinsaturados ainda é obscuro, porém em humanos os supostos mecanismos de ação incluem: inibição da síntese endógena de colesterol, por inibição da HMG-CoA redutase, enzima-chave na síntese de colesterol e aumento da taxa de esterificação de colesterol, por estímulo da enzima ACAT (Garg et al., 1989). Os mecanismos citados podem justificar o efeito da diminuição do colesterol total encontrado neste experimento.

As médias encontradas para LDL-C são próximas aos valores descritos por Watson et al. (1993), que encontraram médias entre 15,47 e $31,71 \mathrm{mg} / \mathrm{dL}$. Observou-se efeito linear $(P=0,0177)$ para a concentração plasmática de
LDL-C; a equação indica diminuição de $0,58 \mathrm{mg} / \mathrm{dL}$ de LDL-C ao aumentar $1 \%$ a inclusão de óleo de soja no concentrado.

Quando há diminuição do colesterol intracelular, ocorre aumento da síntese de receptores para LDL-C e da captação desta lipoproteína do plasma (Grundy, 1996), fato que pode explicar a diminuição no LDL-C neste experimento.

Não foi observado efeito dos níveis de óleo de soja sobre o HDL-C (Tabela 4). As médias de HDL-C (Tabela 4) são maiores que as relatadas por Yamamoto et al. (1979), que encontraram concentrações de 52,20 a $62,26 \mathrm{mg} / \mathrm{dL}$ e Watson et al.(1993), de 44,8 a 58,78 mg/dL, para equinos sem suplementação de gordura dietética. A maior parte do colesterol se apresentou dentro da HDL (Tabela 4), concordando com os dados reportados por Watson et al. (1993).

A concentração de colesterol em VLDL apresentou $(\mathrm{P}=0,057)$ regressão linear crescente, na qual se observou aumento da concentração de VLDL-C ao aumentar a porcentagem de inclusão de óleo de soja (Tabela 4). De acordo com a equação, ao aumentar 1\% no nível de óleo de soja no concentrado, houve aumento de $0,95 \mathrm{mg} / \mathrm{dL}$ na concentração plasmática de VLDL-C. Yamamoto et al. (1979) também relataram médias de VLDL-C de 0,77 a 3,09 mg/dL.

Discordando com os dados desse experimento, Geelen (2001) observou correlação entre os níveis de óleo na dieta e o aumento de colesterol total e HDL-C. O autor justificou o aumento do HDL-C pelo fato de a dieta suplementada com gordura aumentar a atividade da lipoproteína lipase (LPL). Outros autores (McCann et al., 1987; Hambleton et al., 1990; Hallebeek, 2002) confirmaram que a adição de lipídios na dieta de equídeos não tem efeito sobre os níveis plasmáticos de colesterol.

Não foi observado efeito dos níveis de óleo de soja sobre os valores séricos de triglicérides $(\mathrm{P}=0,1228)$, que se mantiveram nos padrões fisiológicos normais para a espécie equina, segundo Bruss (1980).

Tabela 4 - Concentrações séricas de colesterol total, frações de colesterol nas lipoproteínas de densidade alta, densidade baixa e densidade muito baixa e triglicérides

\begin{tabular}{|c|c|c|c|c|c|c|c|c|}
\hline \multirow[t]{2}{*}{ Item } & \multicolumn{4}{|c|}{ Nível de óleo de soja (\%) } & \multirow[t]{2}{*}{ Desvio-padrão } & \multirow[t]{2}{*}{ Probabilidade } & \multirow[t]{2}{*}{ Regressão } & \multirow[t]{2}{*}{$r^{2}$} \\
\hline & 5 & 10 & 15 & 20 & & & & \\
\hline Colesterol & 96,5 & 91,75 & 89,75 & 86,25 & 6,71 & 0,0012 & $99,25-0,65 X$ & 0,3178 \\
\hline \multicolumn{9}{|l|}{ Lipoproteínas } \\
\hline Densidade alta & 71,75 & 69,5 & 70 & 68,75 & 8,87 & 0,1742 & - & - \\
\hline Densidade baixa & 23,35 & 21 & 17,95 & 14,7 & 7,61 & 0,0177 & $26,50-0,58 x$ & 0,1939 \\
\hline Densidade muito baixa & 1,4 & 1,25 & 1,8 & 2,8 & 1,9 & 0,0577 & $0,62+0,95 x$ & 0,0831 \\
\hline Triglicérides & 12 & 11,25 & 14 & 16,5 & 5,67 & 0,1228 & - & - \\
\hline
\end{tabular}




\section{Conclusões}

Nas condições deste experimento, a inclusão de óleo de soja no concentrado não afeta a aceitabilidade, mas influencia a digestibilidade da dieta, principalmente na fração parede celular, e diminui a concentração plasmática de colesterol total e da fração do colesterol na lipoproteina de densidade baixa. O nível máximo de óleo de soja deve ser de $9,5 \%$ em dietas para potros.

\section{Agradecimentos}

\section{À FAPESP, pelo financiamento do projeto.}

\section{Literaura Citada}

BRUSS, M.L. Lipids and ketones. In: KANEKO, J.J. (Ed.) Clinical biochemistry of domestic animals. New York: Academic Press, 1980. p.83-905.

BUSH, J.A.; FREEMAN, D.E.; KLINE, K.H. et al. Dietary fat supplementation effects on in vitro nutrient disappearance and in vivo nutrient intake and total tract digestibility by horses. Journal of Animal Science, v.79, n.1, p.232-239, 2001.

GALBRAITH, H.; MILLER, T.B.; PATON, A.M. et al. Antibacterial activity of long chain fatty acids and the reversal with calcium, magnesium, ergocalciferol and cholesterol. The Journal of Applied Bacteriology, v.34, n.4, p.803-813, 1971.

GARG, M.L.; THOMSON, A.B.R.; CLANDININ, M.T. Effect of dietary fish oil on tissue lipid metabolism. In: CHANDRA, R.K. (Ed.) Health effects of fish and fish oils. St. John's: ARTS Biomedical Publishers and Distributors Limited, 1989. p.53-79.

GEELEN, S.N.J. High fat intake and equine lipid metabolism. 2001. 114f. Thesis (Doctor in Animal Nutrition) - Universidade de Utrecht, Utrecht, 2001.

GRUNDY, S.M. Dietary fat. In: ZIEGLER, E.E.; FILER J.R., L.J. (Ed.) Present knowlegde in nutrition. 7.ed. Washington: ILSI, 1996. p.44-57.

HALLEBEEK, J.M. Dietary control of equine plasma triacylglycerols. 2002. 140f. Thesis (Doctor in Animal Nutritiol) - Universiteit Utrecht, Utrecht, 2002.

HAMBLETON, P.L.; SLADER, L.D.; HAMAR, D.W. et al. Dietary fat and exercise conditioning effect on metabolic parameters in the horse. Journal of Animal Science, v.51, n.6, p.1330-1339, 1990.

HUGHES, S.J.; POTTER, G.D.; GREENE, L.W. et al. Adaptation of Thoroughbred horses in training to a fat supplement diet. Equine Veterinary Journal, v.18, p.349-352, 1995 (suppl.).

JANSEN, W.L.; van der KUILEN, J.; GEELEN, S.N.J. et al. The effect of replacing nonstructural carbohydrates with soybean oil on the digestibility of fiber in trotting horses. Equine Veterinary Journal, v.32, n.1, p.27-30, 2000.
JANSEN, W.L.; GEELEN, J.; KUILEN, V.D. et al. Dietary Soybean oil depresses the apparent digestibility of fiber in trotters when substituted for an isoergetic amount of corn starch or glucose. Equine Veterinary Journal, v.34, n.3, p.302-305, 2002.

JULEN, T.R.; POTTER, G.D.; GREENE, L.W. et al. Adaptation to a fat-supplemented diet by cutting horses. Journal of Equine Veterinary Science, v.15, n.10, p.436-440, 1995.

KANE, E.; BAKER, J.P.; BULL, L.S. Utilization of a corn oil supplemented diet by pony. Journal of Animal Science, v.48, n.5, p.1379-1384, 1979.

KRONFELD, D.S.; HOLLAND, J.L.; RICH, G.A. et al. Fat digestibility in Equus caballus follow a first-order kinetics. Journal of animal science, v.82, n.6, p.1773-1780, 2004.

LEWIS, L.D. Nutrição clínica eqüina: alimentação e cuidados. São Paulo: Roca, 2000. 710p.

LOWRY, G.F. Special Unit and Medical School Laboratory Technicians in New Zealand. A follow-up review and survey of training and qualifications 1970-1975. New Zealand Medicine Journal, v.12, n.5, p.579, 1977.

McCANN, J.S.; MEACHAM, T.N.; FONTENOT, J.P. Energy utilization and blood traits of ponies fed fat-supplemented diets. Journal of Animal Science, v.65, n.4, p.1019-1026, 1987.

MEYER, H.; FLOTHOW, C.; RADICKE, S. Preileal digestibility of coconut fat and soybean oil in horses and their influence on metabolites of microbial origin of the proximal digestive. Archives of Animal Nutrition, v.50, n.1, p.63-74, 1997.

MEYER, M.C.; POTTER, G.D.; EVANS, J.W. et al. Physiologic and metabolic response of exercising horses to added dietary fat. Journal of Equine Veterinary Science, v.9, n.4, p.218-223, 1989.

PALMQUIST, D.L.; JENKINS, T.C. Fat in lactation rations: A review. Journal of Dairy Science, v.63, n.1, p.1-14, 1980.

RESENDE, J.; RESENDE, A.S.C.; LACERDA JR., O.V. et al. Efeito do nível de óleo de milho adicionado à dieta de eqüinos sobre a digestibilidade dos nutrientes. Arquivo Brasileiro de Medicina Veterinária e Zootecnia, v.56, n.1, p.69-73, 2004.

SCOTT, B.D.; POTTER, G.D.; EVANS, J.W. et al. Growth and feed utilization by yearling horses fed added dietary fat. Journal of Equine Veterinary Science, v.9, n.4, p.210-214, 1989.

SILVA, D.J.; QUEIROZ, A.C. Análise de alimentos: métodos químicos e biológicos. 2.ed. Viçosa, MG: Imprensa Universitária UFV, 1998. 235p.

STATISTICAL ANALYSIS SYSTEM - SAS. SAS user's guide: statistics. Versão 5. Cary: 1995.

YAMAMOTO, M.; TANAKA, Y.; SUGANO, M. Lipid composition and cholesterol esterification in serum lipoprotein fraction of the horse, Equus Caballus. Comparative Biochemistry and Physiology, v.63, n.3, p.441-449, 1979.

WATSON, T.D.G.; PACKARD, C.J.; SHEPERD, J. Plasma lipid transport in the horse (Equus caballus). Comparative Biochemistry and Physiology, v.106, n.1, p.27-34, 1993.

WEBB, S.P.; POTTER, G.D.; EVANS, J.W. Physiology and metabolic response of race and cutting horses to added dietary fat. In: EQUINE NUTRITION PHYSIOLOGY SYMPOSIUM, 10. 1987, Fort Collins. Proceedings... Fort Collins, 1987. p.115.

ZEYNER, A. A method to estimate digestible energy in horses feed. Journal of Nutrition, v.132, n.6, p.1771-1773, 2002. 